Seminar Nasional Penelitian dan Pengabdian kepada Masyarakat

Universitas Sang Bumi Ruwa Jurai Tahun 2020

\title{
PEMERIKSAAN HB PADA IBU HAMIL DI PUSKESMAS SITADATADA
}

\author{
Emilia Silvana Sitompul, Juana Linda Simbolon \\ Prodi D-III Kebidanan Tarutung \\ Poltekkes Kemenkes Medan, Sumatera Utara \\ emilia.sitompul1607@gmail.com,mamado.kia@yahoo.com
}

\begin{abstract}
Abstrak
Anemia dalam kehamilan merupakan salah satu penyebab tingginya Angka Kematian Ibu. Anemia dan KEK pada ibu hamil meningkatkan resiko terjadinya bayi lahir premature, Berat Bayi Lahir Rendah, stunting hingga kematian ibu. Anemia kehamilan merupakan masalah nasional "potensial danger to mother and child" yang mencerminkan nilai kesejahteraan sosial ekonomi. Prevalensi anemia ibu hamil di Indonesia $70 \%$ atau 7 dari 10 wanita hamil menderita anemia. Indonesia salah satu negara penderita anemia kehamilan terbanyak. Penanggulangan masalah anemia gizi besi pada ibu hamil dengan pemberian tablet tambah darah (Fe). Selama kehamilan ibu hamil mendapat 90 tablet tambah darah. Untuk mengetahui ibu hamil anemia kami melakukan pengabdian masyarakat dengan memeriksa kadar haemoglobin. Skirining anemia dengan pemeriksaan haemoglobin serta memberikan suplemen besi dan folat. Metode pengabdian dengan melibatkan bidan kordinator dan bidan desa yang terlebih dahulu dilakukan penjajakan serta izin dengan kepala Puskesmas Sitadatada. Hasil Pengabdian ibu hamil dengan anemia 21 orang (52,5\%) dari 40 ibu hamil yang dilakukan pemeriksaan kadar haemoglobin. Ibu hamil anemia jika kadara Hb periksa $\leq 11,5 \mathrm{~g} /$ dl. Pengabdian ini dapat dilakukan secara berkelanjutan untuk mendeteksi masalah gizi pada ibu hamil. Sehingga petugas kesehatan perlu monitoring dan evaluasi.
\end{abstract}

Kata kunci: anemia, ibu hamil, pemeriksaan haemoglobin

\begin{abstract}
Anemia in pregnancy is one of the causes of the high maternal mortality rate. Anemia and KEK in pregnant women increase the risk of premature birth, low birth weight, stunting and even maternal death. Pregnancy anemia is a national problem "potential danger to mother and child" which reflects the value of socioeconomic welfare. The prevalence of anemia in pregnant women in Indonesia is $70 \%$ or 7 out of 10 pregnant women suffer from anemia. Indonesia is one of the countries with the most pregnancy anemia. Overcoming the problem of iron nutrition anemia in pregnant women by giving blood added tablets $(\mathrm{Fe})$. During pregnancy, pregnant women receive 90 plus tablets of blood. To find out anemic pregnant women, we carry out community service by checking their hemoglobin levels. Screening for anemia by checking hemoglobin and giving iron and folate supplements. The service method involved a coordinating midwife and village midwife, which had been assessed beforehand and with permission from the head of the Sitadatada Community Health Center. Results of dedication of pregnant women with anemia 21 people (52.5\%) of 40 pregnant women who were tested for hemoglobin levels. Anemic pregnant women if the $\mathrm{Hb}$ level check is $\leq 11.5 \mathrm{~g} / \mathrm{dl}$. This service can be done on an ongoing basis to detect nutritional problems in pregnant women. So that health workers need monitoring and evaluation.
\end{abstract}

Keywords: anemia, pregnant women, hemoglobin check 


\section{PENDAHULUAN}

Anemia dalam kehamilan merupakan salah satu penyebab tingginya Angka Kematian Ibu. Anemia dan KEK pada ibu hamil meningkatkan resiko terjadinya bayi lahir premature, Berat Bayi Lahir Rendah, stunting hingga kematian ibu. Anemia kehamilan merupakan masalah nasional "potensial danger to mother and child" yang mencerminkan nilai kesejahteraan sosial ekonomi. Anemia pada masa kehamilan merupakan masalah kesehatan yang penting dalam upaya meningkatkan derajat kesehatan masyarakat sehubungan dengan kesehatan ibu dan anak. Anemia pada ibu hamil adalah salah satu faktor yang menjadi indikator pengukuran keberhasilan pembangunan kesehatan suatu bangsa yang menggambarkan kemampuan sosial ekonomi dalam memenuhi kebutuhan kuantitas dan kualitas gizi masyarakat (Arisman, 2010).

Anemia merupakan kondisi yang ditandai dengan penurunan abnormal masa total sel darah merah. Penyebabnya terdiri dari tiga faktor terpenting yaitu kehilangan darah karena pendarahan akut atau kronis, pengrusakan sel darah merah, dan produksi sel darah merah yang tidak cukup banyak. World Health Organization (WHO) melaporkan bahwa prevalensi anemia pada ibu hamil di dunia berkisar rata-rata $14 \%$, di negara industri $56 \%$ dan di negara berkembang antara $35 \%$ $75 \%$. Oleh karena itulah anemia memerlukan perhatian serius dari semua pihak yang terkait dalam pelayanan kesehatan (Manuaba, 2007). Data World Health Organization (WHO) 2010, 40\% kematian ibu di negara berkembang berkaitan dengan anemia dalam kehamilan. Kebanyakan anemia dalam kehamilan disebabkan oleh defisiensi besi dan perdarahan akut. Anemia dalam kehamilan merupakan masalah kesehatan yang utama di negara berkembang dengan tingkat morbiditas tinggi pada ibu hamil. Rata-rata kehamilan yang disebabkan karena anemia di Asia diperkirakan sebesar 72,6\%. WHO 2008 menunjukkan prevalensi anemia pada ibu hamil diperkirakan di Asia sebesar 48,2 \%, Afrika 57,1 \%, Amerika 24,1 \% dan Eropa 25,1 \%. Terkhusus di Indonesia prevalensi anemia ibu hamil adalah $70 \%$ atau 7 dari 10 wanita hamil menderita anemia. Indonesia merupakan salah satu negara dengan jumlah penderita anemia kehamilan terbanyak. Tingginya pravalensinya anemia pada ibu hamil merupakan masalah yang tengah dihadapi pemerintah Indonesia (Adawiyani, 2013).

Konsentrasi $\mathrm{Hb}$ paling rendah didapatkan pada trimester II, yaitu pada usia kehamilan 30 minggu. Pada trimester III terjadi sedikit peningkatan $\mathrm{Hb}$, kecuali pada perempuan yang sudah mempunyai kadar $\mathrm{Hb}$ yang tinggi (> 14,5 g/dl) pada pemeriksaan pertama (Prawirohadjo, 2009). Ibu hamil Trimester III Adalah wanita yang sedang mengandung janin didalam rahim dan usia kehamilan 28-40 minggu dihitung dari hari pertama haid terakhir wanita tersebut. Masa kehamilan terutama trimester III merupakan masa kritis dimana kebutuhan akan zat gizi meningkat. Jika zat besi dalam darah 22 kurang maka kadar hemoglobin akan menurun yang mengakibatkan gangguan dan pertumbuhan janin. Beberapa penelitian menyatakan bahwa kadar $\mathrm{Hb}$ ibu hamil trimester akhir dan tingginya angka anemia pada trimester III dapat mempengaruhi berat badan lahir. Kebutuhan zat besi ibu hamil meningkat pada kehamilan trimester II dan III. Pada masa tersebut kebutuhan zat besi tidak dapat diandalkan dari menu harian saja. Walaupun menu hariannya mengandung zat besi yang cukup, ibu hamil tetap perlu tambahan tablet besi atau vitamin yang mengandung zat besi. Zat besi bukan hanya penting untuk memelihara kehamilan. Ibu hamil yang kekurangan zat besi dapat menimbulkan perdarahan setelah melahirkan, bahkan infeksi, kematian janin intra uteri, cacat bawaan dan abortus.

Pada trimester III, metabolisme basal tetap naik terus. Pada masa ini umumnya nafsu makan baik sekali, dan wanita hamil selalu terasa lapar. Pemeriksaan kenaikan berat badan perlu dilakukan dengan teliti, jangan sampai ibu terlalu gemuk, untuk menghindari kesulitan melahirkan kelak. Pada saat ini pula, kandungan sudah besar sekali sehingga menyebabkan lambung sedikit terdesak untuk mencegah kekurangan unsur-unsur gizi. Pada trimester ini, ibu memerlukan ketenangan dan dukungan dari suami, keluarga dan bidan (Hani, 2010).

Bila makanan yang dikonsumsi mempunyai nilai gizi yang baik, maka status gizi juga baik, sebaliknya bila makanan yang dikonsumsi kurang nilai gizinya, maka dapat menyebabkan kekurangan gizi. Selain itu, perilaku konsumsi makanan seseorang dipengaruhi oleh faktor instrinsik, yaitu faktor-faktor yang berasal dari diri seseorang seperti usia, jenis kelamin, dan 
keyakinan, serta faktor ekstrinsik, yaitu faktor-faktor yang berasal dari luar diri seseorang seperti tingkat ekonomi, pendidikan, tempat tinggal, lingkungan sosial, dan kebudayaan (Jumarlina, 2007). Terjadinya anemia umumnya disebabkan oleh pola makan yang tidak seimbang. Hal ini disebabkan oleh rendahnya angka kesadaran gizi masyarakat khususnya ibu hamil. Wanita hamil merupakan salah satu kelompok yang rentan masalah gizi terutama anemia gizi besi.

Berdasarkan hasil Riskesdas (2018) prevalensi anemia ibu hamil sebesar 48,90\%. Namun demikian keadaan ini mengindikasikan bahwa anemia gizi besi masih menjadi masalah kesehatan masyarakat. Penanggulangan masalah anemia gizi besi saat ini berfokus pada pemberian tablet tambah darah (Fe) pada ibu hamil. Ibu hamil mendapat tablet tambah darah 90 tablet selama kehamilannya. Faktor sosial ekonomi yang rendah juga memegang peranan penting kaitannya dengan asupan gizi ibu selama hamil.

\section{METODE}

Dengan melakukan penjajakan ke Puskesmas terlebih dahulu dengan melibatkan bidan desa dan bidan kordinator. Memetakan jumlah ibu hamil trimester III diwilayah kerja Puskesmas Sitadatada Kecamatan Sipoholon. Memberikan informasi tentang kegiatan pengabdian masyarakat Prodi D-III Kebidanan Tarutung kepada Kepala Puskesmas Sitadatada Kecamatan Sipoholon. Mengumpulkan ibu hamil trimester III diwilayah kerja Puskesmas Sitadatada Kecamatan Sipoholon untuk pelaksanaan pengabdian masyarakat. Metode kegiatan pengabdian diawali dengan perkenalan. Melakukan pendidikan kesehatan tentang anemia menggunakan alat peraga dan powerpoint yang sudah disiapkan. Memberikan kesempatan kepada peserta pengabdian masyarakat untuk mengajukan pertanyaan. Menjawab pertanyaan yang diajukan peserta pengabdian masyarakat. Melakukan pemeriksaan $\mathrm{Hb}$ serta membagi suplemen tambah darah.

Kegiatan yang dilakukan untuk mendeteksi kejadian anemia defisiensi besi (ADB) adalah dengan Pemeriksaan kadar hemoglobin dengan menggunakan alat ukur hemoglobin digital dengan merk Easy Touch GCHb. Untuk mencegah terjadinya ADB pada ibu hamil dan wanita usia subur diberikan suplementasi besi dan folat dan dilakukan juga penyuluhan tentang vitamin dan mineral yang penting sebagai pencegahan terjadinya anemia dan KEK.

\section{HASIL DAN PEMBAHASAN}

Dari 40 ibu hamil yang diperiksa, sebanyak 19 orang adalah ibu hamil dengan Hb Normal dan 21 Ibu Hamil Anemia. Ibu hamil dikatakan menderita anemia jika kadar $\mathrm{Hb} \leq 11,5 \mathrm{~g} / \mathrm{dl}$, ibu hamil yang menderita anemia anemia adalah 21 orang (52,5\%). Usia ibu hamil yang termuda berusia 20 tahun dan yang tertua berusia 42 tahun. Rata-rata usia ibu hamil 31 tahun. Dilihat dari risiko kehamilan berdasarkan usia dimana ibu hamil dengan usia $\leq 20$ tahun dan $>35$ tahun dikatakan berisiko tinggi mengalami komplikasi kehamilan, maka terdapat 9 orang $(22,5 \%)$ ibu hamil yang berisiko tinggi. Ibu hamil yang anemia dan KEK selanjutnya harus mendapatkan pemantauan dari pihak petugas kesehatan agar ibu dapat melahirkan dengan lancar dan bayinya juga selamat.

\section{KESIMPULAN}

Kegiatan pelayanan kesehatan berupa pemeriksaan kadar Hemoglobin dapat mendeteksi anemia pada ibu hamil. Bagi ibu hamil, deteksi dini sangat penting untuk mencegah komplikasi dalam kehamilan. Anemia pada ibu hamil dapat meningkatkan risiko bayi lahir premature, BBLR bahkan kematian ibu dan bayi. Selain skrining, tindakan pencegahan ADB pada ibu hamil adalah dengan pemberian tablet besi dan folat. Saran : 
Seminar Nasional Penelitian dan Pengabdian kepada Masyarakat Universitas Sang Bumi Ruwa Jurai Tahun 2020

1. Agar kegiatan pengabdian masyarakat ini dapat dilakukan secara berkelanjutan dan berbasis pemberdayaan masyarakat dimana mampu menjadikan kader posyandu sebagai kader, bidan desa pendeteksi masalah gizi masyarakat.

2. Kepada petugas kesehatan agar meneruskan informasi tentang makanan pencegah anemia defisiensi besi dan makanan yang perlu dikurangi karena menghambat penyerapan zat besi.

3. Diperlukan monitoring dan evaluasi berkelanjutan terhadap program pengabdian masyarakat ini

\section{UCAPAN TERIMAKASIH}

Penulis mengucapkan terima kasih kepada Kepala Puskesmas Sitadada, Bidan Kordinator, Bidan Desa yang telah memberi dukungan dalam pengabdian masyarakat ini serta Ibu hamil yang telah bersedia dilakukan pemeriksaan kadar haemoglobin.

\section{DAFTAR PUSTAKA}

Amiruddin,dkk, 2004 Studi Kasus Kontrol Faktor Biomedis Terhadap Kejadian Anemia Ibu Hamil Di Puskesmas Bantimurung Maros Tahun 2004. Artikel Ilmiah Makassar

Arisman, M.B, 2010 Gizi Dalam Daur Kehidupan. Buku Ajar Ilmu Gizi EGC Jakarta

Jumarlina. 2007 Gambaran faktor Penyebab Rendahnya Cakupan Fe3 pada Ibu Hamil di Puskesmas Maniangpajo Kab. Wajo. Universitas Hasanuddin Makassar

Manuaba, 2010 Ilmu Kebidanan, Penyakit Kandungan, Keluarga Berencana Untuk Pendidikan Bidan. Penerbit EGC Jakarta.

Prawihardjo, S.2010 Ilmu Kandungan. Penerbit Yayasan Bina Pustaka Jakarta

Riskesdas, 2013.Riset Kesehatan Dasar. Departemen Kesehatan RI Jakarta

Winkjosastro,H, 2010 Ilmu Kebidanan. Penerbit Pustaka Rihma Yogyakarta 